Relations industrielles

Industrial Relations

\title{
Trice, Harrison M., Occupational Subcultures in the Workplace
}

\section{Laurent Bélanger}

Volume 50, numéro 1, 1995

URI : https://id.erudit.org/iderudit/051004ar

DOI : https://doi.org/10.7202/051004ar

Aller au sommaire du numéro

Éditeur(s)

Département des relations industrielles de l'Université Laval

ISSN

0034-379X (imprimé)

1703-8138 (numérique)

Découvrir la revue

Citer ce compte rendu

Bélanger, L. (1995). Compte rendu de [Trice, Harrison M., Occupational Subcultures in the Workplace]. Relations industrielles / Industrial Relations, 50(1), 235-236. https://doi.org/10.7202/051004ar

Tous droits réservés (C) Département des relations industrielles de l'Université Laval, 1995
Ce document est protégé par la loi sur le droit d'auteur. L'utilisation des services d'Érudit (y compris la reproduction) est assujettie à sa politique d'utilisation que vous pouvez consulter en ligne.

https://apropos.erudit.org/fr/usagers/politique-dutilisation/ 
musiques implantés dans des quartiers en difficulté et Jean Baptiste de Foucauld, en quelques pages sommaires, rappelle les principaux enjeux de tous ces projets.

La troisième partie se veut plus politique. $\grave{A}$ partir d'une analyse classique des problèmes de la reconnaissance institutionnelle par les pouvoirs publics dans la situation allemande actuelle, Adalbert Evers pose en conclusion la question tout à fait pertinente du divorce grandissant entre les idéologies politiques libérales et la nécessité de reconnaître un rôle clef aux institutions de solidarité. À partir de quelques expériences québécoises et avec beaucoup de pragmatisme, Benoit Lévesque dégage quelques formes de reconnaissance institutionnelle effectivement mises en œuvre outre-Atlantique. Laurent Thévenot, pour sa part, montre l'inadaptation des catégories de pensée administratives et statistiques pour raisonner l'économie solidaire. Enfin, Bernard Perret, se fondant sur l'expérience du Conseil de l'Évaluation, tente d'expliciter l'ampleur des changements culturels nécessaires au niveau de l'État et de la haute fonction publique pour parvenir à cette solidarité.

Comme c'est bien souvent le cas dans de tels ensembles à plusieurs voix, on peut facilement gloser sur les différences de points de vue entre les auteurs. Les définitions avancées de l'économie solidaire et de la cohésion sociale sont effectivement diverses et variées. Probablement ne sont-elles pas véritablement antinomiques, mais certainement pas non plus totalement cohérentes. C'est bien ainsi que progresse le débat public.

Plus surprenant, par contre, est le fait que l'ensemble de ces auteurs semblent partager, au moins implicitement, l'idée que les catégories de penser les liens entre l'" économique " et le "social " telles que définies par l'économie classique auraient été admises communément. Après tout, il existe bien tout un courant de pensée, allant des philosophes et des anthropologues aux économistes, qui considère bien que les catégories de la pensée, tout autant que celles de la pratique sont des produits sociaux et que même les structures économiques les plus fondamentales, tout comme les modèles économiques les plus abstraits, sont des produits historiques et contingents. Le choix de considérer l'économie comme la science des rapports des hommes aux choses ("à la nature") n'est spécifique qu'à une des branches de la théorie économique. Qu'elle soit aujourd'hui la branche dominante ne doit pas pour autant faire oublier qu'il en existe d'autres et que l'établissement même de cette domination fut un long travail social. $\grave{A}$ ainsi reconnaître les apports de tels précurseurs, et à tenter de comprendre pourquoi on les aurait oubliés, on pourrait peut-être se donner les moyens de penser réellement les raisons sociales pour lesquelles la société française considère les problèmes sociaux actuels comme inéluctables.

JeAN SAGLIO CNRS, Université Lyon II

\section{Occupational Subcultures in the Workplace}

par Harrison M. Trice, Ithaca, New York, ILR Press, 1993, 287 p., ISBN 087546-302-9 (cloth) and ISBN 0-87546-303-7.

$\mathrm{Au}$ cours des deux dernières décennies, nous avons assisté au développement fulgurant d'une littérature sur la réalité culturelle des organisations. Règle générale, ces publications, tant d'ordre conceptuel que d'ordre empirique, ren- voient à une vision globale, monolithique de la culture organisationnelle, faisant peu ou pas de place à l'expression d'idéologies, de valeurs ou de croyances qui sont partagées par des groupements restreints au sein même des 
organisations, cela en marge de la culture dominante. Le présent ouvrage vise justement à contrer ou à corriger cette tendance en s'attaquant à l'étude des phénomènes de sous-cultures à l'intérieur des organisations. L'auteur s'est intéressé plus particulièrement à l'étude des représentations, des significations, des valeurs partagées par les différentes catégories socioprofessionnelles qu'on retrouve dans les grandes organisations. Des catégories, telles que les professionnels spécialisés dans une branche particulière du savoir et des pratiques administratives, des directions supérieures d'entreprises, des cadres intermédiaires, des cadres subalternes, voire même des catégories cols blancs et cols bleus.

La première partie de l'ouvrage met l'accent sur l'étude du phénomène culturel propre à une catëgorie occupationnelle en adaptant une définition de la culture élaborée par des anthropologues et appliquée jadis aux organisations dans leur ensemble. On peut constater que les valeurs, les croyances, le langage diffèrent au passage d'une catégorie occupationnelle à une autre et donnent forme au comportement des membres appartenant à la catégorie. Ceci se traduit extérieurement par l'adoption d'un langage approprié, par des rites de passage distincts et par d'autres mécanismes de socialisation.

La deuxième partie vise à mettre en évidence la dynamique culturelle inhé- rente à l'articulation difficile des relations entre les différentes catégories occupationnelles. À ce sujet, les travaux d'Elton Mayo et de ses collègues avaient déjà signalé la présence de groupes informels au sein des organisations dans la catégorie ouvrière. On se souvient que ces groupes partageaient des visions et des normes différentes de celles de la direction de l'entreprise sous étude, à un point tel qu'on en est venu à voir ces groupes en marge de l'organisation formelle ou en opposition. Dans cette même partie de son ouvrage, l'auteur déborde largement la réalité des groupes informels pour prêsenter une typologie et des modes d'adaptation qui surviennent au sein des interactions entre, par exemple, les souscultures des professionnels et celles des directions générales.

L'auteur en vient ainsi à la fin de son analyse à fairę ressortir les implications de ces différences au plan de la gestion de la diversité culturelle des organisations. Il réussit donc à mettre en évidence que les occupations constituent elles-mêmes des cultures, que l'étude de cette réalité à été fort négligée, due en grande partie à l'engouement qu'on a développé à l'endroit d'une vision plutôt globale de la réalité culturelle des organisations.

\section{LAURENT BÉLANGER} Université Laval

\section{Critique du droit du travail}

par Alain SUPIOT, Paris, P.U.F., 1994, coll. "Les voies du droit ", 280 p., ISBN 2-13-046113-1.

L'ouvrage est d'un apport particulier. Comme l'indique sa prēsentation, "le propos de ce livre n'est pas de décrire le dernier état [d'un droit de travail] en perpétuel changement, mais d'en démonter les ressorts et saisir le principe de son réglage, c'est-à-dire d'en faire la critique au sens philosophique du terme ". Axé sur le développement historique du droit du travail français, il n'hésite pas à sortir de ce champ dès qu'un autre droit national significatif apporte un éclairage essentiel sur le phénomène, qu'il s'agisse, selon le cas, des droits italien, anglais, américain, mais, avant tout, allemand. Il reprend ainsi plusieurs textes antérieurs de l'auteur, du plus récent ("Le travail, liberté partagée", (1993) Droit social 715 , à sa thèse de doctorat, Le juge et le droit du travail, th. 